RELACult - Revista Latino-Americana de Estudos em Cultura e Sociedade e-ISSN 2016/Atual: 2525-7870 | e-ISSN 2015/2016: 2447-018X

\title{
Una mirada brasileña hacia el Vivir Bien/Buen Vivir: A cobertura da Folha de S. Paulo sobre a reforma constitucional da Bolívia
}

\author{
Una mirada brasileña hacia el Vivir Bien/Buen Vivir: La cobertura de \\ Folha de S. Paulo sobre la reforma constitucional de Bolivia
}

\author{
A Brazilian look towards Living Well/Good Living: Folha de S. Paulo \\ coverage of the constitutional reform of Bolivia
}

\author{
Domingos Alves de Almeida ${ }^{1}$
}

\begin{abstract}
Yo soy la noche, la mañana. Yo soy el fuego, fuego en la oscuridad. Soy pachamama, soy tu verdade. Yo soy el canto, viento de la libertad. Yo soy el cielo, la inmensidad. Yo soy la tierra, madre de la eternidade. (Vientos Del Alma - Mercedes Sosa)
\end{abstract}

\begin{abstract}
Resumo
Este artigo tem por objetivo analisar a abordagem da imprensa brasileira sobre a reforma constitucional boliviana, a partir da cobertura do jornal Folha de S. Paulo, um dos maiores e mais influentes jornais brasileiros, tomando como recorte temporal os meses de janeiro e fevereiro de 2009, período em que a nova Constituição da Bolívia foi colocada para votação e aprovada em referendo nacional. Como suporte metodológico, recorremos à pesquisa bibliográfica, revisão de literatura e a Análise de Discurso (AD) de orientação francesa. Para a fundamentação teórica adotamos a perspectiva de Friggeri (2014), Quijano (2012), Walsh (2008), Mamani (2013), Bautista (2013), Céspedes (2010), Acosta, (2008) e outros. E, no que concerne ao campo jornalístico, utilizamos os preceitos da Teoria Construcionista da Notícia (SOUSA, 2002), com o intuito de refletir sobre a operacionalização das empresas de mídia na "fabricação" das notícias.
\end{abstract}

Palavras-Chave: Reforma Constitucional; Bolívia; Folha de S. Paulo; Discurso.

\section{Resumen}

Este artículo tiene por objetivo analizar el enfoque de la prensa brasileña sobre la reforma constitucional boliviana, a partir de la cobertura del diario Folha de S. Paulo, uno de los mayores y más influyentes diarios brasileños, tomando como recorte temporal los meses de enero y febrero de 2009, período en que la nueva Constitución de Bolivia fue colocada para votación y aprobada en referéndum nacional. Como soporte metodológico, recurrimos a la investigación bibliográfica, revisión de literatura y el Análisis de Discurso (AD)

\footnotetext{
${ }^{1}$ Mestrando do Programa de Pós Graduação em Integração Contemporânea da América Latina - ICAL e cursando Especialização em Relações Internacionais Contemporâneas, pelo Instituto Latino-Americano de Economia, Sociedade e Política - ILAESP, da Universidade Federal da Integração LatinoAmericana - UNILA. Graduado em Comunicação Social com Habilitação em Jornalismo pela Universidade Federal do Maranhão (UFMA), Campus de Imperatriz (2015). É membro do Grupo de Pesquisa Memórias, Diversidades e Identidades Culturais (CCSST/UFMA), do Grupo de Pesquisa em Convergência e Narrativas Audiovisuais (CONNAU CCSST/UFMA) e Jornalismo, Mídia e Memória (JOIMP - CCSST/UFMA). Pesquisador do Projeto Governando contra as notícias: o primeiro ano do governo Flávio Dino nas páginas do jornal O Estado do Maranhão. É Membro da Coordenação Técnica do Centro Latino-Americano de Estudos em Cultura (CLAEC). É Assessor de Comunicação e Professor voluntário de Artes do Centro de Cultura Negra Negro Cosme de Imperatriz (MA). Atualmente estuda Comunicação, Política e Poder na América Latina, com ênfase em televisão. E-mail: domingos.jzufma@gmail.com.
} 

e-ISSN 2016/Atual: 2525-7870 | e-ISSN 2015/2016: 2447-018X

de orientación francesa. Para la fundamentación teórica adoptamos la perspectiva de Friggeri (2014), Quijano (2012), Walsh (2008), Mamani (2013), Bautista (2013), Céspedes (2010), Acosta, (2008) y outros. En lo que concierne al campo periodístico, utilizamos los preceptos de la Teoría Construccionista de la Noticia (SOUSA, 2002), con el propósito de reflexionar sobre la operacionalización de las empresas de medios en la "fabricación" de las noticias.

Palabras-clave: Reforma Constitucional; Bolivia; Folha de S. Paulo; Discurso.

\begin{abstract}
This article aims to analyze the focus of the Brazilian press on the Bolivian constitutional reform, based on the coverage of the newspaper Folha de S. Paulo, one of the largest and most influential Brazilian newspapers, taking as a temporary cut the months of January and February 2009, when the new Constitution of Bolivia was placed for voting and approved in a national referendum. As a methodological support, we resorted to bibliographical research, literature review and French Discourse Analysis (AD). For the theoretical basis we adopt the perspective of Friggeri (2014), Quijano (2012), Walsh (2008), Mamani (2013), Bautista (2013), Céspedes (2010), Acosta, (2008) and others. Regarding the journalistic field, we used the precepts of the Constructor Theory of the News (SOUSA, 2002), with the purpose of reflecting on the operationalization of the media companies in the "manufacture" of the News.
\end{abstract}

Keywords: Constitutional Reform; Bolivia; Folha de S. Paulo; Discourse.

\title{
1. Introdução
}

Nas últimas duas décadas, na América Latina e, em especial na América do Sul, houve um interessante processo linear de mudanças políticas, com a vitória de políticos com orientação à esquerda ou, pelo menos, de caráter progressista. As mudanças políticas começaram com a eleição de Hugo Chávez na Venezuela em 1999. Chávez ficou no poder até 2013, ano de sua morte, e foi sucedido pelo vice Nicolás Maduro, que segue no poder atualmente.

Lula foi o seguinte expoente da esquerda latino-americana a chegar ao poder em 2002 no Brasil, após vencer José Serra, e em 2006, foi reeleito ao derrota Geraldo Alckmin, ambos representantes da direita no país. O presidente brasileiro foi sucedido em 2010 por Dilma Rousseff, primeira mulher eleita presidenta do Brasil que, em 2016, pouco mais de um ano após a reeleição, sofreu um golpe parlamentar conduzido pela direita, e articulado pelo vicepresidente, Michel Temer.

Na Argentina, nesse mesmo intervalo de tempo, Néstor Kirchner foi eleito presidente em 2003, ficou no poder até 2007, quando sucedido por sua esposa Cristina Kirchner, que ocupou a Casa Rosada por dois mandatos consecutivos (2007-2011 e 2011-2015). Em 2015, o candidato de Kirchner foi derrotado pelo atual presidente do país, o empresário direitista, Mauricio Macri.

Em 2005 os bolivianos integraram esse movimento histórico da esquerda na América do Sul, ao elegerem com maioria absoluta, o líder sindical Evo Morales, primeiro presidente de origem indígena e que permanece no poder até os dias de hoje. Na sequência, em 2006, os 

e-ISSN 2016/Atual: 2525-7870 | e-ISSN 2015/2016: 2447-018X

equatorianos elegeram o ex-presidente Rafael Correa que deixou o poder em 2017, depois eleger seu sucessor, Lenín Moreno.

No Paraguai, Fernando Lugo foi eleito em 2008, mas foi retirado do poder, por meio de um golpe parlamentar em 2012. O último presidente a ser eleito nessa configuração progressista na América do Sul, antes das investidas neoconservadora na região, foi Pepe Mujica, em 2009 no Uruguai. Mujica se transformou numa das grandes referências progressistas na América Latina, sendo admirado por intelectuais, políticos e militantes sociais de distintos países.

Esses países supracitados alcançaram avanços consideráveis; após a chegada dos presidentes de orientação progressista ao poder. Alguns inclusive, refundaram seus Estados, e aprovaram novas constituições, substituindo o formato hegemônico e vigente de "Estado liberal moderno" (FRIGGERI, 2014), por um Estado Plurinacional-Intercultural-Decolonial, com a gênese da cosmovisão dos povos originários, ou seja, uma alternativa "a la colonialidad global del poder y a la colonialidad/modernidad/eurocentrada/" (QUIJANO, 2012, p. 46), que rege a maioria dos Estados-Nação na América Latina.

Bolívia e Equador são os dois países que trataram de repensar e refundar seus projetos de Estado e sociedade uni-nacional, colonial e excludente (Walsh, 2008), incorporando concepções de complementariedade entre os povos e a harmonia com a natureza como princípios norteadores da política estatal.

A nova Constitución Política del Estado Plurinacional de Bolivia foi aprovada em referendo nacional no dia 25 de janeiro de 2009, com mais de $60 \%$ dos votos. Ao longo das discussões para a elaboração da carta constitucional e no período de campanha pela sua aprovação, o presidente Evo Morales enfrentou a oposição articulada politicamente e com fortes instrumentos de poder em seu favor, como por exemplo, os meios de comunicação de massa.

Com receio de perder privilégios e possibilitar a construção de um Estado popular e intercultural, a elite boliviana tentou impedir os avanços da nova Constituição do País, fazendo ecoar suas demandas, inclusive no Brasil, onde a imprensa elitista e conservadora, tomada por preconceitos e desconhecimento sobre a proposta constitucional boliviana, tratava do assunto com certo desprezo e até discriminação.

Nesse sentido, temos como objetivo analisar a abordagem da imprensa brasileira sobre a reforma constitucional boliviana, a partir da cobertura do jornal Folha de S. Paulo, um dos maiores e mais influentes jornais brasileiros, tomando como recorte temporal os meses de janeiro e fevereiro de 2009, período em que a nova Constituição da Bolívia foi colocada para votação e aprovada em referendo nacional. 
Como suporte metodológico, recorremos à pesquisa bibliográfica, pesquisa documental e a Análise de Discurso (AD) de orientação francesa. Para a fundamentação teórica adotamos a perspectiva de Friggeri (2014), Quijano (2012), Walsh (2008), Mamani (2013), Bautista (2013), Céspedes (2010), Acosta, (2008) e outros. No que concerne ao campo jornalístico, utilizamos os preceitos da Teoria Construcionista (SOUSA, 2002) da notícia, com o intuito de refletir sobre a operacionalização das empresas de mídia na "fabricação" das notícias.

A Análise de Discurso francesa tem como função revelar os sentidos ocultos produzidos pelos sujeitos falantes, através da linguagem e materializados nos textos, ou seja, os discursos. Aquilo que está verbalizado, seja na oralidade ou na escrita, não revela literalmente o que está dito. Para que o não dito seja identificado e compreendido faz-se necessária fazer uma análise aprofundada a partir do que está materializado, dito.

Para Orlandi (2010), a análise discursiva é um processo de desmontagem - do texto para saber como foi montado, para revelar as ausências que dizem tanto quanto às presenças. Nesse sentido, a autora reforça que a AD procura "ouvir, naquilo que o sujeito diz, aquilo que ele não diz, mas que constitui igualmente os sentidos de suas palavras" (ORLANDI, 2010, p. 59). As falas dos sujeitos externam discursos que trazem marcas ideológicas impossíveis de serem identificadas sem o auxílio de um prisma aguçado - a AD -. É para revelar essas marcas que a Análise de Discurso vai além do que está materializado.

Para a Teoria Construcionista (SOUSA, 2002), as notícias são resultados de um "processo jornalístico de produção de informação", intencional. Assim, as notícias resultam da construção da realidade, representando, apenas, alguns aspectos do real. Considerando que o profissional da comunicação, ao produzir uma notícia ele realiza recortes do fato, enfocando determinado aspecto.

Sousa (2002) reforça que não se trata de uma transposição dos fatos, para os meios de comunicação, mas sim, de "uma construção humana baseada na linguagem, seja ela verbal ou de outra natureza (como a linguagem das imagens)" (SOUSA, 2002, p. 03). Ainda nesse aspecto, o autor desmonta a concepção de que as notícias são espelhos da realidade.

A notícia não espelha a realidade porque as limitações dos seres humanos e as insuficiências da linguagem o impedem. Por isso, a notícia contenta-se em representar parcelas da realidade, independentemente da vontade do jornalista, da sua intenção de verdade e de factualidade. (SOUSA, 2002, p. $05)$.

Em sua atuação cotidiana, o jornalista segue determinadas regras no processo de produção das notícias. A realidade veiculada pelos meios de comunicação é resultante da 
interação de diversos fatores que envolvem o profissional da comunicação (natureza pessoal, social, ideológica, cultural, histórica, do meio físico e dos dispositivos tecnológicos).

\section{Metamorfose da Folha de S. Paulo}

O jornal Folha de S. Paulo representa a síntese da falsa metamorfose da imprensa, especialmente no Brasil. Criticada inclusive por outros veículos de comunicação respeitados internacionalmente (The Guardian; The Independent; The Economist; Euronews; Al Jazeera; teleSUR; El País; The New York Times; The Wall Street Journal; The Washington Post, entre outros), a mídia brasileira, capitaneando certa tendência da mídia latino-americana, possui lado político e partidário muito bem definido na sua atuação. Embora alguns expoentes da imprensa nacional insistam na imparcialidade jornalística, a práxis se encarrega de desconstruir esses discursos.

A falsa metamorfose da imprensa que trazemos aqui para reflexão tem a ver com a capacidade que os meios de informação possuem de se "transformar" politicamente ao longo dos tempos, inclusive ensaiando mudanças em sua postura editorial. No entanto, essa "transformação" à qual se submete a mídia é estratégica e visa, unicamente, impregnar-se de uma força/movimento político/a emergente para garantir sua permanência em uma posição privilegiada ao lado do poder, como no caso da Folha de S. Paulo que se posicionou favorável ao golpe militar de 1964:

Após o golpe militar, a Folha se mostrou entusiasmada com o novo momento da política nacional, e até se posicionou publicamente favorável ao governo dos militares. Preocupada em manter-se ativa no mercado e sanar os problemas financeiros, a empresa buscou caminhar ao lado do "progresso" e do "desenvolvimento econômico" do país, lemas publicizados pela ditadura (ALMEIDA, 2015, p. 20).

A saudação da Folha à chegada dos militares ao Palácio do Planalto foi uma posição adotada com expertise, possibilitada pelo espaço privilegiado que o jornal ocupava naquele momento na sociedade, o que lhe permitiu antever alguns passos dos rumos que o país iria tomar e, com sagacidade, articular uma forma para resolver parte de seus problemas internos, principalmente econômicos.

Nesse sentido, Almeida (2015, p, 20) reforça que "a busca do Grupo Folha pelo crescimento econômico e por sua consolidação, enquanto empresa capitalista capaz de gerar lucro, coincide com o período de instauração do Regime Militar no Brasil”. Complementando Almeida (2015), Dias (2013, p. 51) reforça que "a grande expansão tecnológica da empresa, 

e-ISSN 2016/Atual: 2525-7870 | e-ISSN 2015/2016: 2447-018X

momento em que o jornal obtém lucros expressivos, se deu exatamente durante o período caracterizado pelos anos de chumbo do regime".

Com o endurecimento das medidas de censura e o surgimento de movimentos massivos contra o regime ditatorial, como Diretas Já, a Folha rompeu com o poder vigente dos ditadores e se alinhou ao movimento democrático. No entanto, o jornal não adotou essa postura por acreditar na causa que a população defendia nas ruas ou por desacreditar na ditadura, que havia defendido por duas décadas e de quem foi beneficiária de privilégios. O jornal tomou a iniciativa após constatar o desgaste da ditadura diante da proporção das manifestações. Foi uma oportunidade para ganhar adeptos, respaldo e respeito:

Com postura política definida ora para a direita, ora para a esquerda, sempre reformulando sua linha editorial e se ajustando ao contexto que se apresentava mais favorável ao momento, a Folha buscava se manter ao lado de quem estava melhor posicionado no complexo cenário político da época (ALMEIDA, 2015, p. 20).

Conforme explica Taschner (1992), o impresso “jogava dos dois lados” e seguia a direção dos "novos ventos" que sopravam no obscuro período ditatorial. Atento a esse novo momento político, o jornal reformula sua política editorial, se posicionando em defesa do "apartidarismo" e da "independência jornalística". Com esse discurso se engajou na campanha Diretas Já, vindo a tornar-se referência desse movimento, sendo elevado ao posto de o "jornal das diretas" (DIAS, 2011):

\footnotetext{
Do ponto de vista da orientação política, apoiou o Golpe de 1964, como quase toda a grande imprensa [...] Deu cobertura às manifestações estudantis de 1968, apoiando-as discretamente enquanto não surgiu a luta armada. Seus editoriais eram "inócuos e anódinos" e foram suspensos com a escalada da censura. O jornal fez autocensura, mantendo-se em low profile durante todo o período do milagre. [...] Com o fim desses e a emergência do plano Golbery-Geisel de "distensão", que, segundo Duarte procurou cooptar a grande imprensa de um modo geral, a Folha de S. Paulo, percebendo a direção dos novos ventos, reformulou sua linha editorial. Com isso começou a caminhar mais para a esquerda, não obviamente no sentido de se tornar socialista, mas no de passar a defender, primeiro timidamente e depois com mais ousadia um capitalismo moderno e não selvagem, e a redemocratização do regime político (TASCHNER, 1992, p. 186).
}

Passada a convulsão nacional e reestabelecida a democracia, o jornal se desfaz de seu caráter popular adotado durante a campanha pelas eleições Diretas e realinha seus princípios aos da elite política e econômica, voltando a ser, politicamente, o que havia sido antes, uma das muitas idas e vindas da Folha de S. Paulo. Nos anos que antecederam as eleições de 1989, esse jornal, juntamente com toda a grande imprensa, se encarregou de apresentar o até então 

e-ISSN 2016/Atual: 2525-7870 | e-ISSN 2015/2016: 2447-018X

desconhecido, Fernando Collor, à sociedade brasileira e em 1992, tratou de se unir ao coro do movimento "Caras Pintadas" que defendia o impeachment do presidente brasileiro na época.

Algo similar está acontecendo atualmente. Após defender, inclusive através de editoriais, o golpe contra a Presidenta Dilma Rousseff e, em seguida se colocar como favorável ao governo do então vice-presidente, Michel Temer, agora apresenta sinais de inconformidade e ensaia romper com a gestão. Resta saber para qual direção os "novos ventos" estão encaminhando o jornal que, conforme já foi mostrado, é um veículo que se adapta às novas realidades, mas não perde a essência elitista.

O jornal Folha de S. Paulo surgiu oficialmente em 1960 com a unificação da Folha da Noite (1921), Folha da Manhã (1925) e Folha da Tarde (1949). Atualmente é editado pela empresa Folha da Manhã S.A, de propriedade do Grupo Folha, pertencente à Família do empresário Octávio Frias (ALMEIDA, 2015).

É um dos maiores jornais do país, tendo ocupado durante décadas a primeira posição em volume de tiragem e circulação. Somente em 2010 é ultrapassado pelo jornal de Minas gerais, Super Notícia, mas retoma a liderança em 2012 e 2014. Atualmente ocupa a terceira posição, atrás do jornal $O$ Globo, com as seguintes tiragens em 2015: Súper Notícia com 249.297; O Globo com 193.079 e Folha de S. Paulo 189.254 (ANJ, 2015).

No que diz respeito às características político-editoriais, a Folha se autodefine como "um órgão formador de opinião. Sua força se mede pela capacidade de intervir no debate público e, apoiado em fatos e informações exatas e comprovadas, mudar convicções e hábitos" (FOLHA DE S. PAULO, 2015, p. 02).

Dentre as coberturas jornalísticas feitas pelo jornal, há significativa prioridade para o assunto político. A principal e mais volumosa editoria do veículo é a de política, que recebe o sugestivo nome de Primeiro Caderno que, com suas 12 páginas, aborda assuntos nacionais e internacionais com diferentes enfoques.

\section{Desenvolvimento, Vivir Bien/Buen Vivir e o Estado Plurinacional da Bolívia}

O dia 25 de janeiro de 2009 marca um segundo momento histórico no século XXI para a população boliviana. Depois de terem elegido o primeiro presidente indígena do país, nossos vizinhos andinos aprovaram, por meio de referendo nacional, a nova Constituição do país com $61,43 \%$ de votos. Baseada na cosmovisão dos povos originários, a Constitución Política del Estado Plurinacional de Bolivia, a exemplo do que tinha feito o Equador em 2008, refunda o 

e-ISSN 2016/Atual: 2525-7870 | e-ISSN 2015/2016: 2447-018X

Estado e fortalece o movimento do novo constitucionalismo sul-americano, conforme nos dá conta, Catherine Walsh (2008):

Por primera vez en América del Sur, hay dos Estados - Ecuador y Bolivia - que recientemente se definen como plurinacionales e interculturales. Estas nuevas autodefiniciones son resultado de los procesos plurales y participativos de las Asambleas Constituyentes, procesos que han tomado con seriedad las propuestas y el pensar de los movimientos, los pueblos y las comunidades ancestrales buscando que ellas ayudan a la construcción de una nueva articulación y convergencia de sociedad y Estado para todos los ecuatorianos y bolivianos (WALSH, 2008, p. 143).

Nesse contexto de mudanças de paradigmas políticos e sociais, a partir da proposta de inovação das práticas dos Estados supracitados, ditos modernos na atualidade, foram adotadas palavras diferentes, embora similares (vivir bien e buen vivir), para definir o mesmo processo de alteração estrutural, advindo da cosmovisão de seus respectivos povos originários:

Vivir bien, decimos en Bolivia, buen vivir dicen en el Ecuador. Más allá de si está
bien traducido o no, tratamos de explicar lo mismo desde el Allin Kawsay, Sumaj
Kawsay o desde el Suma Qamaña, conceptos que se entienden fácilmente desde
nuestra cosmovisión, pero no desde la cosmovisión occidental, por lo tanto también
tenemos que explicar previamente nuestra cosmovisión (MAMANI, 2013, p. 46/47).

Neste trabalho, não problematizaremos as possíveis contrariedades e distinções da perspectiva conceitual de buen vivir e vivir bien, adotaremos os dois pontos de vistas de forma confluentes, considerando que trazem consigo a mesma cosmovisão dos povos originários, com suas particularidades contextuais.

Embora estejam escritas de formas diferentes nas Constituições da Bolívia e do Equador, Quijano (2008) explica que se trata de:

Un complejo de prácticas sociales orientadas a la producción y a la reproducción democráticas de una sociedad democrática, un otro modo de existencia social, con su propio y específico horizonte histórico de sentido, radicalmente alternativos a la colonialidad global del poder y a la colonialidad/modernidad/eurocentrada (QUIJANO, 2012, p. 46).

Para os bolivianos, conforme é destacado na própria apresentação da nova Carta Magna, a mesma representa um pacto de convivência entre todos os povos do país e é um projeto de sociedade e Estado para as próximas gerações, enfatizando, sobretudo, a necessidade de integrar e incluir a população indígena, parcela mais marginalizada e excluída do projeto estatal de sociedade vigente até 2009 . Iniciativa que promove a recuperação da identidade, cultura e pensamento indígena originário, que aos poucos foi se perdendo. 

e-ISSN 2016/Atual: 2525-7870 | e-ISSN 2015/2016: 2447-018X

Não se tratou somente de incluir e integrar, a articulação do Movimento Indígena Boliviano, permitiu que os indígenas se tornassem os principais agentes propositores do novo momento constitucionalista do país. Sobre essa contribuição do Movimento Indígena ao processo constitucional da Bolívia, Friggeri (2014) explica que:

Lo central de ese pensamiento propio y lo que le da un verdadero carácter novedoso dentro de la tradición constitucionalista es justamente el aporte que realiza centralmente el Movimiento Indígena, esto es: lo que le da un verdadero carácter aunque incipiente y ambiguo todavía en muchos aspectos - de "alteridad constitucional”. (FRIGGERI, 2014, p. 174).

Nesse sentido, a Constituição boliviana reconhece os povos indígenas como agentes centrais na construção desse processo de refundação do Estado, para superar o modelo decadente de Estado-nação, moderno liberal e atribui aos indígenas o papel fundamental na configuração social, política, econômica e cultural, não somente na atualidade, mas, principalmente, na estruturação histórica do país:

\begin{abstract}
El pueblo boliviano, de composición plural, desde la profundidad de la historia, inspirado en las luchas del pasado, en la sublevación indígena anticolonial, en la independencia, en las luchas populares de liberación, en las marchas indígenas, sociales y sindicales, en las guerras del agua y de octubre, en las luchas por la tierra y territorio, y con la memoria de nuestros mártires, construimos un nuevo Estado (PREÁMBULO - CONSTITUCIÓN POLÍTICA DEL ESTADO PLURINACIONAL DE BOLIVIA, 2009, p. 07).
\end{abstract}

Como verificamos nesse trecho do Preâmbulo da Constituição, os povos originários e parte de seu histórico de resistência são colocados na centralidade do novo Estado que se edifica. Entretanto, isso não exclui a parcela da população não indígena, uma vez que reconhece que o povo do país é de composição plural.

$\mathrm{Na}$ primeira parte da Constituição Boliviana, que instrumentaliza as Bases Fundamentales del Estado: Derechos, Deberes y Garantías, o artigo I do primeiro capítulo já apresenta os delineamentos básicos desse novo Estado, que refuta o modelo liberal e busca na cosmovisão dos povos originários a essência para as bases do constitucionalismo que passa a reger o país:

Bolivia se constituye en un Estado Unitario Social de Derecho Plurinacional Comunitario, libre, independiente, soberano, democrático, intercultural, descentralizado y con autonomías. Bolivia se funda en la pluralidad y el pluralismo político, económico, jurídico, cultural y lingüístico, dentro del proceso integrador del país (ARTÍCULO I - CONSTITUCIÓN POLÍTICA DEL ESTADO PLURINACIONAL DE BOLIVIA, 2009, p. 11). 

e-ISSN 2016/Atual: 2525-7870 | e-ISSN 2015/2016: 2447-018X

O país inova, principalmente, ao incluir em sua definição o Plurinacional, Comunitário e intercultural. Atendendo a reivindicações históricas dos povos indígenas, que são negados e negligenciados pelos Estados Nacionais eurocentrados.

O artigo 306 da quarta parte da Constituição boliviana, que dispõe sobre Estructura y organización Económica del Estado, traz um dos pontos mais significativo desse constitucionalismo decolonial proposto pelo país. Está expresso que "el modelo económico boliviano es plural y está orientado a mejorar la calidad de vida y el vivir bien de todas las bolivianas y los bolivianos" (ARTÍCULO 306 - CONSTITUCIÓN POLÍTICA DEL ESTADO PLURINACIONAL DE BOLIVIA, 2009, p. 121).

Dispor o modelo econômico para melhorar a qualidade de vida e o vivir bien, figura como uma proposta significativa e inovadora, considerando que se trata de um país capitalista, onde "la forma de vida que se produce no garantiza la vida de todos sino sólo de los poderosos, a costa de la vida de todos y, en definitiva, de la vida del planeta" (BAUTISTA, 2013 p. 12).

Assim, a Bolívia sugere que a riqueza produzida pelo país estará destinada ao benefício da própria população, promovendo o vivir bien e não o viver melhor, como corriqueiramente se prega nos Estados modernos neoliberais:

Vivir Bien significa complementarnos y no competir, compartir y no aprovecharnos del vecino, vivir en armonía entre las personas y con la naturaleza. El Vivir Bien no es lo mismo que el vivir mejor, el vivir mejor que el otro. Porque para el vivir mejor, frente al prójimo, se hace necesario explotar, se produce una profunda competencia, se concentra la riqueza en pocas manos. Vivir mejor es egoísmo, desinterés por los demás, individualismo (CÉSPEDES, 2010, p. 08).

Céspedes (2010) ainda complementa esse contraponto do vivir bien em relação ao viver melhor, a partir da compreensão, a qual se fundamenta a Constituição do Estado Plurinacional boliviano:

Bolivia plantea el Vivir Bien, no un vivir mejor a costa del otro, sino un Vivir Bien basado en la vivencia de nuestros pueblos. Vivir Bien es vivir en comunidad, en hermandad, y especialmente en complementariedad. Donde no haya explotados ni explotadores, donde no haya excluidos ni quienes excluyan, donde no haya marginados ni marginadores (CÉSPEDES, 2010, p. 08).

Esse prisma de sociedade, é um oriundo da cosmovisão dos povos originários da Bolívia, para quem "el "vivir bien" es el horizonte que da sentido a nuestro caminar el proceso" (BAUTISTA, 2013 p. 21). Horizonte que visa eliminar os sustentáculos desse modelo de convivência social decadente, no qual se constroem antagonismos, colocando os povos nos extremos, ricos e pobres. 

e-ISSN 2016/Atual: 2525-7870 | e-ISSN 2015/2016: 2447-018X

Nesse aspecto, o vivir bien propõe a relação harmoniosa entre os seres humanos entendendo que "lo más importante no es la persona individual. Lo más importante es la comunidad, donde todas las familias vivimos juntas" (CÉSPEDES, 2010, p. 08). E Como eixo central dessa harmonia, coloca-se, fundamentalmente, a natureza, Pachamama, como a base constitucional dessa concepção de mundo:

El vivir bien nos invita a retornar a nuestra naturaleza, preservar el equilibrio de la vida y despertar en nuestras propias capacidades para vivir plenos. Expresar nuestras capacidades naturales nos va a devolver la plenitud y permitirnos dejar de sufrir en el afán de competir; en el afán de tener todo lo que alrededor te dicen que debes tener, y en actividades que no tienen nada que ver con nosotros mismos (MAMANI, 2013, p. 48).

Para os povos originários, a natureza é um sujeito vivo, de direito, não passível de objetificação. O caminho para a sobrevivência da espécie humana não é o da exploração dessa natureza, mas sim, o da convivência respeitosa e consonante, estabelecendo uma relação salutar de filhos (os povos) e mãe (a natureza), onde ambos se cuidam mutuamente:

Vivir Bien es recuperar la vivencia de nuestros pueblos, recuperar la Cultura de la Vida y, recuperar nuestra vida en completa armonía y respeto mutuo con la madre naturaleza, con la Pachamama, donde todo es VIDA, donde todos somos uywas, criados de la naturaleza y del cosmos, donde todos somos parte de la naturaleza y no hay nada separado, donde el viento, las estrellas, las plantas, la piedra, el rocío, los cerros, las aves, el puma, son nuestros hermanos, donde la tierra es la vida misma y el hogar de todos los seres vivos (CÉSPEDES, 2010, p. 10).

Ainda nesse sentido, Acosta (2008) chama a atenção para o fato de que, tomando como base os preceitos cósmicos de seus povos originários, a Bolívia incluiu a natureza na nova Constituição, como sujeito de direito. Para o autor, essa é uma alternativa para se começar a pensar outra forma de sociedade, inclusive produtiva e sustentável:

Nótese la diferencia con la visión de la Pacha Mama, de nuestros pueblos originarios, que ven a la Naturaleza no como objeto, sino como sujeto vivo. Y eso es algo que queremos rescatar y transmitir en nuestra nueva Constitución al poner a la Naturaleza como sujeto de derechos, para comenzar a plantearnos otras formas de organizar la sociedad. Si lo entendemos de esa manera, podemos llegar a tener una lógica social muy interesante, incluso productiva, sustentable. Nosotros no vemos a la madera, los bananos, el agua, los minerales, el subsuelo sólo como mercancías o como recursos para ser explotados, pues esa sería una visión muy parecida a la visión de los traficantes de esclavos. Sin lugar a duda, va a ser una tarea difícil y compleja, y es uno de los grandes retos en los que estamos empeñados en buscar transformaciones (ACOSTA, 2008, p. 08). 
Esse sentimento de pertencimento dos povos originários à natureza- lhes dá o discernimento para refutar o sistema exploratório do capitalismo neoliberal, que lança mão do acúmulo e sobrepõe o capital ao ser humano. Optam pelo modelo econômico e de desenvolvimento, que parte do pressuposto de que, em qualquer atividade econômica, o ser humano deve ser o centro.

Caracterizando esse novo momento político e social, especificamente na América do Sul, Quijano (2012) destaca que o "[Vivir Bien] Bien Vivir, hoy, solo puede tener sentido como una existência social alternativa, como una des/colonialidad del Poder" (QUIJANO, 2012, p. 46). Devolver para as mãos dos povos originários esse poder colonizado e eurocêntrico, que os marginaliza, e buscar refundar esse Estado a partir de suas próprias perspectivas, é uma forma de romper com essa hegemonia de poder ocidentalizante:

Estamos, pues, inmersos en un proceso de completa reconfiguración de la colonialidad global del poder, del patrón de poder hegemónico en el planeta. Se trata, en primer término, de la aceleración y profundización de una tendencia de re-concentración del control del poder (QUIJANO, 2012, p. 50).

Essa reconfiguração do poder global ocorre porque o modelo de poder hegemônico está imerso em uma crise estrutural, o que requer alternativas para sua superação. Essa hegemonia que está entrando em colapso; ou pelo menos se fragilizando cada vez mais e de forma cíclica é baseada na exploração predatória dos recursos naturais sem, contudo, permitir a regeneração da natureza que tem respondido de forma violenta ao desgaste sofrido.

Voltar às origens em busca de alternativas ao modelo de sociedade e de desenvolvimento atual se dá por uma necessidade existencial dos povos indígenas originários, apagados ao longo dos anos, a partir de 1492, de todos os processos históricos da América Latina, mas, sobretudo, para garantir a sobrevivência da espécie humana. Conforme explica Céspedes (2010, p. 10/11) "tenemos que volver a ser, porque la colonización ha hecho que nosotros dejemos de ser. Muchos de nosotros hemos dejado de ser, ya no somos. Ahora queremos nuevamente volver a ser qamiri ${ }^{2}$, volver a ser iyambae ${ }^{3}$, volver a ser qhapaj ".

As reformas realizadas nas Constituições do Equador e da Bolívia, sendo essa última, tomada como fonte de análise desse trabalho, são as gêneses do que segundo Friggeri (2014),

\footnotetext{
${ }^{2}$ Qamiri é uma expressão aymara para se referir a uma pessoa que vive bem (CÉSPEDES, 2010).

${ }^{3}$ A palavra Iyambae é utilizada pelos guaranis, para determinar uma pessoa que vive bem, que se desenvolve plenamente de maneira natural, sem estar submetida a ninguém (Idem).

${ }^{4}$ Qhapaj é uma pessoa que vive bem, para os quechuas (Idem).
} 
tem sido chamado de nuevo constitucionalismo latino-americano, que apresenta uma profunda originalidade e alteridade latino-americana. Ademais disso:

\begin{abstract}
El nuevo constitucionalismo latinoamericano constituye un inmenso, apasionante y hermoso desafío para la política y la academia de nuestra región. Constituye también un elemento convocante para un auténtico proceso de unión latinoamericana, de construcción de una Patria Grande plurinacional, pero con naciones que rompen los limites coloniales de nuestros actuales estados y que también rompen los limites eurocêntricos de nuestra academia. Por ser tan importante, tiene y va a tener una poderosísima oposición sobre todo en la medida en que se pueda avanzar. Oposición en la política y en la academia. Su realización requiere una toma de posición epistémico-política (FRIGGERI, 2014, p. 186).
\end{abstract}

Em suma, o novo constitucionalismo latino-americano, capitaneado por Equador e Bolívia na América Latina, traz consigo um conjunto de expectativas tanto no âmbito político como epistêmico, considerando que esse movimento constitucionalista surge como alternativa ao modelo vigente, que apresenta graves sintomas de saturação.

O vivir bien/buen vivir, para além do âmbito político, possui as estruturas de uma sociedade possível. Uma sociedade que já existe na materialidade cotidiana dos nossos povos originários, mas que requer muita vontade política para que seja ampliada e efetivada como a visão norteadora das políticas de Estado.

\title{
4. Olhar da Folha de S. Paulo para a constituinte boliviana
}

O acervo da presente pesquisa consta de 21 matérias do jornal Folha de S. Paulo sobre a Bolívia, veiculadas entre 01 de janeiro de 2009 a 31de fevereiro de 2009. Esse recorte temporal foi adotado por se tratar do período em que a Constituição da Bolívia foi discutida, elaborada e aprovada na Assembleia Constituinte, bem como votada em referendo nacional, confirmando sua aprovação.

O corpus do estudo consta de matérias de gêneros variados (notícias, reportagens, entrevistas, notas e etc.). Desse quantitativo, tomamos como recorte as matérias que abordaram especificamente o referendo constitucional boliviano, sendo 5 reportagens e duas entrevistas, que estão dispostas na tabela 01:

Tabela 01 - Informações sobre as matérias analisadas

\begin{tabular}{|c|c|c|l|c|}
\hline Jornal & Editoria & Matérias & \multicolumn{1}{|c|}{ Título } & $\begin{array}{c}\text { Data de } \\
\text { publicação }\end{array}$ \\
\hline $\begin{array}{l}\text { Folha de S. } \\
\text { Paulo }\end{array}$ & $\begin{array}{l}\text { Primeiro } \\
\text { Caderno }\end{array}$ & M1 & Lula dá apoio à Carta de Morales; & $16 / 01 / 2009$ \\
\hline$-/-$ & $-/-$ & M2 & $\begin{array}{l}\text { Bolívia vota hoje Constituição que causou convulsão } \\
\text { no país; }\end{array}$ & $25 / 01 / 2009$ \\
\hline
\end{tabular}


RELACult - Revista Latino-Americana de Estudos em Cultura e Sociedade e-ISSN 2016/Atual: 2525-7870 | e-ISSN 2015/2016: 2447-018X

\begin{tabular}{|c|c|c|l|l|}
\hline$-/-$ & $-/-$ & M3 & 'Nova Carta é muito mais inclusiva', diz antropólogo; & $25 / 01 / 2009$ \\
\hline$-/-$ & $-/-$ & M4 & $\begin{array}{l}\text { Texto afugenta investidores, diz ex-vice-presidente } \\
\text { (entrevista); }\end{array}$ & $25 / 01 / 2009$ \\
\hline$-/-$ & $-/-$ & M6 & Colivianos aprovam nova Constituição "indígena"; & $25 / 01 / 2009$ \\
\hline$-/-$ & $-/-$ & M7 & $\begin{array}{l}\text { Metade do país está descontente, diz líder opositor } \\
\text { (entrevista); }\end{array}$ \\
\hline
\end{tabular}

Fonte: o autor com informações do jornal Folha de S. Paulo.

Para desenvolver a análise de discurso do jornal Folha de S. Paulo, sobre a reforma constitucional boliviana, buscamos identificar a formação discursiva articulada pelo periódico, em torno do assunto. A formação discursiva "se define como aquilo que em uma formação ideológica dada - ou seja, a partir de uma posição dada em uma conjuntura sócio-histórica dada - determina o que pode e deve ser dito" (ORLANDI, 2010, p. 43).

Ainda segundo Orlandi (2010), a formação discursiva "permite compreender o processo de produção dos sentidos, a sua relação com a ideologia e também dá ao analista a possibilidade de estabelecer regularidades no funcionamento do discurso" (ORLANDI, 2010, p. 43). Nesse aspecto, os aportes da Teoria Construcionista contribuem para a compreensão do aparato que funciona em volta da ação noticiosa, ao nos possibilitar entender ""por que é que as notícias são como são (e não são de outra maneira)?", "por que temos as notícias que temos (e não temos outras notícias)?", "como circula a notícia e que efeitos gera?"'” (SOUSA, 2002, p. 01).

A partir da averiguação e análise prévia das notícias da Folha de S. Paulo levantadas para essa pesquisa, verificamos que ela articula um conjunto de fatores que conflui para uma formação discursiva que a coloca na posição de questionadora da legitimidade e até da autoridade do presidente boliviano, Evo Morales, para conduzir o processo de reforma da Constituição do país, ao reforçar o posicionamento da oposição que é contrária às mudanças na Carta.

É possível verificar essa formação discursiva a partir da forma como as matérias são intituladas, de como estão dispostas nas páginas do periódico, bem como as fontes que foram evocadas, além da própria articulação textual para a construção dos discursos, inclusive lançando mão do uso de formas textuais incomuns na prática jornalística, como a aliteração.

O primeiro destaque para essa cobertura da Folha de S. Paulo sobre a reforma constituinte da Bolívia, é para o enfoque recorrente dado à divisão política interna do país, onde a oposição ao presidente Evo Morales, aparece com força suficiente para impedir o mandatário de realizar as aspirações políticas pretendidas: 

e-ISSN 2016/Atual: 2525-7870 | e-ISSN 2015/2016: 2447-018X

\begin{abstract}
A Constituição boliviana chega ao referendo após um acordo entre governo e parte da oposição no Congresso [para] modificar mais de cem artigos no texto e rejeitada por governadores de três departamentos. Pelo acordo, Morales prometeu desistir de concorrer a dois novos mandatos após a aprovação da nova Carta, que estabelece a reeleição (por só um período). Assim, só poderá disputar a eleição prevista para dezembro de 2009 (M1, 2009).
\end{abstract}

Além da falha de coesão textual no trecho acima, Evo Morales é apresentado como refém de um grupo opositor que rejeita as modificações na Carta Magna, fazendo-o, inclusive, desistir de concorrer à reeleição por mais de uma vez. Com abordagem superficial sobre as mudanças políticas em curso no país andino, a Folha comete falhas jornalísticas que podem, até, ser consideradas propositais, como ao intitular uma matéria da seguinte forma: "Bolívia vota hoje Constituição que causou convulsão no país".

Com essa aliteração formada pelas palavras "Constituição" e "convulsão" no título, e conhecendo a priori, a orientação política-editorial do periódico, entendemos que a construção textual, aparentemente errônea, não se trata meramente de um jogo de palavras despretensioso, mas sim, de dar associar o momento constitucional um caráter negativo. Esse entendimento é ratificado no texto que sucede:

\footnotetext{
Com a memória viva da aguda crise política e de violentos confrontos no ano passado, cerca de 3,8 milhões de bolivianos irão novamente às urnas hoje para decidir sobre a aprovação do projeto de constituição impulsionado por Evo Morales. A proposta amplia a presença do Estado na Economia, aumenta os direitos da população indígena, estabelece diversos tipos de autonomia e introduz a reeleição presidencial. Para chegar até o referendo de hoje, a Bolívia atravessou uma jornada dramática e violenta. Em dezembro de 2001, após mais um ano de paralização, a bancada governista da Assembleia constituinte aprovou a Carta sem a oposição e longe da sede, a cidade de Sucre, onde protestos deixaram três oposicionistas mortos e dezenas de feridos. Ao longo do ano passado, departamentos governados pela oposição promoveram referendos para aprovar espécies de Constituições regionais outorgando mais autonomia em relação ao poder central. Em setembro, a tensão culminou num violento confronto no departamento de Pando, com um saldo de 13 mortos, a maioria camponeses pró-Morales (M2, 2009).
}

Além de trazer essa possível fragmentação na estrutura política do país, o jornal destacou, também, as suposições de grupos religiosos insatisfeitos com os direcionamentos progressistas adotados pela nova Constituição: "Porta-vozes católicos reclamaram da retirada da menção à sua religião da Carta, enquanto líderes protestantes afirmaram que o texto ao mencionar vagamente 'direitos sexuais e reprodutivos' abriria a porta para a aprovação do casamento homossexual e do aborto" (M2, 2009). 

e-ISSN 2016/Atual: 2525-7870 | e-ISSN 2015/2016: 2447-018X

As ilações dos grupos religiosos aparecem na cobertura da Folha unicamente para reforçar a visão da elite boliviana, tomada pelo jornal como a merecedora de prevalecer em detrimento da defendida pelo presidente Evo Morales.

É interessante destacar que o periódico traz a perspectiva de um dos mais importantes intelectuais da Bolívia. Por meio de uma entrevista feita por telefone, um enviado especial do veículo a Potosí, que não é identificado, entrevista o antropólogo e sacerdote Jesuíta, Xavié Albó, que apresenta uma análise breve sobre os avanços que trará a nova Constituição boliviana. A entrevista foi intitulada "Nova Carta é muito mais inclusiva', diz antropólogo".

O que chama a atenção nesse caso é que, em sequência ao diálogo com Albó, o mesmo enviado da Folha a Potosí, entrevista o ex-vice-presidente boliviano, Victor Hugo Cárdenas, contrário à reforma da constituição. O diálogo foi intitulado de "Texto afugenta investidores, diz ex-vice-presidente". Com essa disposição textual em suas páginas, a Folha busca deslegitimar as falas do antropólogo e o discurso de Morales, ao trazer um personagem do cenário político, indígena como o Presidente e que, teoricamente, possui conhecimentos práticos da efetividade ou não da nova Carta, caso aprovada.

A primeira pergunta da Folha a Cárdenas, “por que o sr é contrário a este projeto constitucional?", é uma daquelas que, no universo jornalístico, chamamos de pergunta de préentrevista, que é feita somente em duas possibilidades: para que o entrevistador se prepare para entrevista principal ou para se obter as informações que aparecem na introdução da entrevista, depois de pronta.

Geralmente, o tipo de informação adquirida com perguntas chapa branca como essa, pode ser encontrada através de outras entrevistas, pronunciamentos ou comunicados do personagem entrevistado, principalmente quando se trata de figuras públicas. Em se tratando de Hugo Cárdenas, político da direita boliviana, com fácil acesso aos meios hegemônicos de comunicação, é inconcebível abrir os microfones para ouvir uma resposta corriqueira, possibilitada por uma pergunta de tão pouca relevância. A resposta dada, já é um scrip roteirizado conforme podemos asseverar no trecho a seguir:

Há razões de procedimentos e de conteúdo. O trâmite desta Constituinte não estava de acordo com a Lei de Convocatória, nem com as leis do país. O texto deveria ter sido aprovado em Sucre, mas foi levado a outro município, a um recinto militar, o que é ilegal. E, depois, no Congresso, em meados de outubro, um grupo de parlamentares do MAS (Movimento ao Socialismo) e do Podemos (oposição) se reúnem e modificam cerca de metade dos 411 artigos. O Congresso não tem essa faculdade legal, porque usurpa a Assembleia Constituinte. Com relação ao conteúdo. O primeiro problema é que este texto cria uma cidadania de primeira e outra de terceira. Cidadãos como eu, de origem indígena, temos mais direitos que os não indígenas. Isso contrária 

e-ISSN 2016/Atual: 2525-7870 | e-ISSN 2015/2016: 2447-018X

a Declaração Universal dos Direitos do Homem, no qual está o princípio da Igualdade (CÁRDENAS, M4, 2009).

Como se nota, os questionamentos contrários à Constituição apresentados pelo entrevistado são basicamente partidários, considerando que Cárdenas faz parte do grupo de oposição ao presidente Evo Morales. No que diz respeito à extensão das garantias de direitos aos povos indígenas, a Folha não só ecoa os discursos contrários a essa prerrogativa, como os toma para si, ao destacar que, "Bolivianos aprovam nova Constituição “indígena"”.

O título já diz muita coisa para uma sociedade como a brasileira onde o periódico circula, em que os indígenas são vistos e tratados como a escória social e empecilho ao "progresso econômico". É um título de má fé, que não condiz com a realidade proposta pela Constituição, considerando que não foram retirados diretos de uns - não indígenas - em benefício de outros - indígenas.

O problema real, que não está evidente na cobertura do periódico, é que a Constituição boliviana mexe nos privilégios da elite, garantindo cidadania de fato aos povos originários do país. Novamente o Jornal volta a enfatizar a divisão política que existe no país, em uma clara tentativa de deslegitimar os movimentos de mudança política conduzidos por Morales:

\footnotetext{
Os primeiros resultados voltaram ainda a mostrar a profunda divisão política entre o antiplano, reduto de Morales e as terras baixas. O sim venceu nos departamentos de La Paz (81\%), Oruro (73\%), Potosí (78\%), Cochabamba (64\%). Em Tarija e Chuquisaca, havia empate técnico, segundo resultados preliminares divulgados pela TV estatal. Já a oposição voltou a demonstrar força no leste e no norte do país. Em Santa Cruz (leste), o departamento (Estado) mais rico do país, o "não" venceu com $65 \%$. Resultados semelhantes foram registrados ainda nos departamentos amazônicos de Beni (68\%) e Pando (60\%), segundo a TV estatal (M5, 2009).
}

Mesmo após a aprovação da nova Constituição boliviana no referendo do dia 25 de janeiro (2009), a Folha segue em sua investida no sentido de retirar a credibilidade do processo político que ocorre no país vizinho. A penúltima matéria dessa análise tem como título "Carta norteará diálogo com oposição, diz Evo". O subtítulo, "Líderes de Santa Cruz rejeitam texto aprovado em referendo; presidente boliviano diz que negociará aplicação da constituição sem alterar teor", é seguido por um texto destacado em negrito que diz, "votação do sim é inferior à que o governo esperava; dúvida agora é sobre como implantar texto que exigirá leis complementares" (M6, 2009).

O destaque para esse ponto se deve ao fato de que na mesma página, logo abaixo dessa matéria, a Folha traz uma entrevista com o empresário Branko Morinkovic, presidente do Comitê Cívico Pró-Santa Cruz. Entidade que reúne a elite econômica da região mais rica do 

e-ISSN 2016/Atual: 2525-7870 | e-ISSN 2015/2016: 2447-018X

país. Na entrevista, o empresário diz que a vitória do "não", nos quatro departamentos do leste do país, tira a legitimidade da nova constituição nesses lugares.

Mais uma vez a Folha peca na condução da entrevista ao fazer perguntas confortáveis, que permitem ao entrevistado responder tranquilamente, sem ter suas versões sobre o fato confrontadas. "Qual a sua leitura do resultado?” é a pergunta que abre o diálogo, composto por mais quatro questões, onde Morinkovic expressa seu ponto de vista sobre o resultado do referendo:

O resultado indica que metade do país não está contente com essa Constituição e reflete as duas visões de país que há neste momento na Bolívia. Uma visão que quer autonomia nesta região do país, que representa $70 \%$ da economia boliviana. O ocidente quer o sistema chavista, socialista, nosso respeito a eles, mas devemos encontrar um pacto para que esta Bolívia possa conviver em paz com as visões que tem (M7, 2009).

Em outras palavras, trata-se de uma visão separatista, em que a Folha não demonstra qualquer preocupação em garantir que essa postura ganhe destaque em suas páginas. A carência de vozes favoráveis ao processo constitucional boliviano ou a forma periférica como elas aparecem na cobertura jornalística desse impresso é mais um ponto a ser reforçado, como forma de sustentar que o periódico atuou contra a reforma constituinte do país vizinho

\section{Conclusões}

A Folha, ao centrar-se na posição de agente questionador da legitimidade política do presidente boliviano Evo Morales, a frente da articulação para conduzir o processo de reforma Constituinte do país, reforça e ecoa o posicionamento do grupo oposicionista que, naquele momento, é contrário às mudanças na Carta. Isso fica evidente na cobertura do jornal que, corriqueiramente, representa o poder político do país vizinho como algo fragmentado, atribuindo, inclusive, autoridade a diferentes figuras que divergem das ações progressistas que podem ser materializadas, com a Constituição aprovada.

Essas construções discursivas já elencadas certificam, ainda, que este jornal impresso representou o processo Constitucional como algo confuso, propenso a ser fracassado, considerando que há uma oposição muito poderosa no campo contrário- e, que detém sob sua tutela, a maior parte das riquezas produzidas pelo país. São constatações asseguradas quando se observa que a Folha alimenta o desejo separatista da oposição ao destacar com ênfase o "baixo" desempenho do "sim" no referendo que aprovou a Constituição. 

e-ISSN 2016/Atual: 2525-7870 | e-ISSN 2015/2016: 2447-018X

Assim, entendemos que a Folha deixou claro seu posicionamento político, alinhado à direita boliviana, que tem seus discursos prevalecidos na cobertura feita sobre o assunto. Para isso, foca-se nos discursos efusivos dos opositores de Morales, deixando de apresentar os vários pontos a serem modificados e as propostas inovadoras da Carta. Em um dos poucos destaques às mudanças, coloca como o ponto chave da nova Constituição, a possibilidade de Evo Morales se reeleger, como se este fosse o ponto central e mais relevante desse constitucionalismo.

Portanto, não resta dúvida de que a Folha de S. Paulo atuou como agente político, somando forças à oposição política boliviana, ainda que externamente, desde o Brasil, no sentido de desfavorecer as intenções de Evo Morales, caracterizando a postura ideológica do periódico em relação aos grupos políticos da direita na América do Sul.

\section{Referências}

Almeida, D. A. A representação do poder político no maranhão no Jornal Folha de São Paulo. Monografia (Graduação em Comunicação Social) Curso de Bacharelado em Comunicação Social com habilitação em Jornalismo, Centro de Ciências Sociais, Saúde e Tecnologia de Imperatriz Maranhão (CCSST) / Universidade Federal do Maranhão (UFMA), 2015.

ACOSTA, A. El «buen vivir» para la construcción de alternativas. Transcripción de la conferencia dictada em la clausura del Encuentro Latinoamericano del Foro Mundial de Alternativas, realizado en Quito del 26 al 29 de febrero de 2008. Revista Casa de las Américas No. 251, Quito, 2008.

BAUTISTA, R. El nuevo horizonte civilizatorio del "Vivir Bien". In: FARAH, I.; TEJERINA, V. (org.). Vivir bien: Infancia, genero y economia: Entre la teoría y la práctica. Weinberg, La Paz - Bolivia: UNICEF, 2013.

BOLÍVIA. Constitución Política del Estado Plurinacional de Bolivia. La Paz, Bolívia: República de Bolívia, 2009.

CÉSPEDES, D. C. Hacia la reconstrucción del Vivir Bien. Revista América Latina em movimentos, Bolívia: ALAI, 2010.

CRONOLOGIA. Folha de S. Paulo. São Paulo, 2004. Disponível em: http://almanaque.folha.uol.com.br/ditadura_cronologia.htm. Acesso em: 12 mar 2015.

DIAS, A. B. As memórias da Folha de S. Paulo durante o regime militar no Brasil: o processo de construção de uma identidade a partir de suas lembranças e esquecimentos. Revista Estudos em Comunicação, v. 10, p. 127-153, 2011. Disponível em:

http://www.ec.ubi.pt/ec/10/pdf/EC10-2011Dez-07.pdf. Acesso em: 22 mar 2014.

FRIGGERI, F. P. “Alteridad constitucional”. Nuevo constitucionalismo y principios indígenas: de la incoherencia a la revolución. Cadernos Prolam/USP 13 (25): p. 173-187, São Paulo, 2014. 
MAIORES Jornais do Brasil. Associação Nacional de Jornais. Brasília, 2014. Disponível em: http://www.anj.org.br/maiores-jornais-do-brasil/. Acesso em 10 de nov de 2015.

MAMANI, F. H. Cosmovisión andina y Vivir Bien. In: FARAH, I.; TEJERINA, V. (org.), Vivir bien: Infancia, genero y economia: Entre la teoría y la práctica. Weinberg, La Paz Bolivia: UNICEF, 2013.

ORLANDI, E. Análise de Discurso: Princípios \& Procedimentos. São Paulo: Pontes Editores, 2010.

QUIJANO, A. "Bien vivir": entre el "desarrollo" y la des/colonialidad del poder. Revista VIENTO SUR Número 122/Mayo 2012.

TASCHNER, G. Folhas ao Vento: análise de um conglomerado jornalístico no Brasil. $1^{\mathrm{a}}$. ed.

- Rio de Janeiro: paz e terra, 1992.

WALSH, C. Interculturalidad, plurinacionalidad y decolonialidad: las insurgencias políticoepistémicas de refundar el Estado. Bogotá - Colombia: Tabula Rasa. No. 9: 131-152, juliodiciembre 2008.

Edições do jornal Folha de S. Paulo consultadas

FOLHA DE S. PAULO. São Paulo. 16, jan. 2009

FOLHA DE S. PAULO. São Paulo. 25, jan. 2009

FOLHA DE S. PAULO. São Paulo. 25, jan. 2009

FOLHA DE S. PAULO. São Paulo. 25, jan. 2009

FOLHA DE S. PAULO. São Paulo. 27, jan. 2009

FOLHA DE S. PAULO. São Paulo. 27, jan. 2009 